\title{
Effect of chronic kidney disease on individual and population medical expenditures in the Japanese population
}

\author{
Aya Higashiyama ${ }^{1,2}$, Tomonori Okamura ${ }^{1}$, Makoto Watanabe $^{1}$, Yoshitaka Murakami ${ }^{2}$, Hidemi Otsuki $^{3}$, \\ Noriko Adachi ${ }^{3}$, Chiaki Kaneko ${ }^{3}$, Emi Uehara ${ }^{3}$, Akira Okayama ${ }^{4}$ and Hirotsugu Ueshima ${ }^{2}$
}

Chronic kidney disease (CKD) is associated with increased risk of cardiovascular disease (CVD), and may also lead to an increase in medical expenditures. The effect of CKD on individual and population medical expenditures was examined in a Japanese cohort study. The participants included 4026 Japanese National Health Insurance beneficiaries aged 40-74 years living in one city, who had no history of major CVD. They were classified into three categories according to their glomerular filtration rate (GFR) at the baseline survey, and their total medical expenditures were followed-up for 3 years. The arithmetic and geometric means of the cumulative medical expenditures were calculated for each category. The geometric mean was also expressed after adjusting for several confounding factors using analysis of covariance. The CKD-related medical expenditures attributable to the participants with mild $(60 \leqslant \mathrm{GFR}<90)$ or moderate $(30 \leqslant \mathrm{GFR}<60)$ kidney dysfunction were compared with those of participants with normal (GFR $\geqslant 90)$ kidney function. There was a negative correlation between the GFR category and the arithmetic and geometric means of personal medical expenditures (adjusted geometric mean: GFR $\geqslant 90,167879$ yen; $60 \leqslant \mathrm{GFR}<90,210660$ yen; and $30 \leqslant \mathrm{GFR}<60,330050$ yen). The CKD-related medical expenditures accounted for 11.5 and $6.5 \%$ of the total medical expenditures for the participants with mild and moderate kidney dysfunction, respectively. The prevention of mild CKD is very important for containing medical expenditures. Appropriate strategies, such as regular creatinine measurement, are needed for early detection of CKD.

Hypertension Research (2009) 32, 450-454; doi:10.1038/hr.2009.51; published online 17 April 2009

Keywords: CKD-related medical expenditures; cohort study; GFR

\section{INTRODUCTION}

Chronic kidney disease (CKD) was developed as a concept to prevent end-stage renal disease (ESRD) and other related medical complications. ${ }^{1}$ According to the Japanese Society for Dialysis Therapy, the incidence of patients with ESRD starting chronic dialysis therapy has been greater than 2000 per million population since $2005 .{ }^{1}$ This large number of ESRD patients could be just the tip of the iceberg of an increasing number of patients with CKD. In the United States, the estimated 19 million persons who have CKD is a significantly larger population than the 450000 with ESRD. ${ }^{2}$

Earlier studies reported that CKD was associated with increased mortality and morbidity of cardiovascular disease (CVD) ${ }^{3-5}$ Considering the large estimated numbers of individuals with CKD and their high risk for CVD, medical expenditures of people with CKD may be an important concern. However, to our knowledge, no study has investigated the medical expenditures of people with CKD in communities.

Accordingly, we investigated the cumulative total medical expenditures after stratification by the estimated glomerular filtration rate
(GFR) categories using data of National Health Insurance (NHI) beneficiaries in Tanba City, located in the western part of Japan. Our $a$ priori hypothesis was that the estimated GFR was negatively correlated with medical expenditures. Furthermore, we investigated the proportion of the excess cumulative total medical expenditures of participants with CKD.

\section{METHODS}

Medical expenditures in Japan

Medical expenditures in Japan were based on a public medical insurance institution, 6,7 which was mainly classified into two insurance systems until March 2008; recently, a third system for elderly persons aged 75 years or more was enrolled. Everyone living in Japan was required to enroll in one of the two insurance systems. One was for employees and their dependents. The other was called the NHI system, which was for self-employed individuals, such as farmers and fishermen, as well as for retirees and their dependents; this system was controlled by local municipalities. The NHI system covered $41 \%$ of the total Japanese population in $2005 .{ }^{8}$ All prices were strictly controlled by a

${ }^{1}$ Department of Preventive Cardiology, National Cardiovascular Center, Suita, Japan; ${ }^{2}$ Department of Health Science, Shgia University of Medical Science, Otsu, Japan;

${ }^{3}$ Tanba City Office, Tanba City, Japan and ${ }^{4}$ The First Institute for Health Promotion and Health Care, Japan Anti-Tuberculosis Association, Tokyo, Japan

Correspondence: Dr A Higashiyama, Department of Preventive Cardiology, National Cardiovascular Center, Fujishirodai 5-7-14, Suita, Osaka 565-8565, Japan.

E-mail: ahigashi@hsp.ncvc.go.jp

Received 29 August 2008; revised 9 February 2009; accepted 1 March 2009; published online 17 April 2009 
fee schedule that was set by the National Government and calculated on a 'fee-for-service' basis. The fee schedule was constant, independent of the insurance system. Furthermore, the same fee schedule applied to all clinics and hospitals that were approved to provide medical services under the public medical insurance system.

\section{Study population}

The study cohort consisted of Japanese NHI beneficiaries, aged 40-74 years, living in Tanba City in Hyogo Prefecture, in the western part of Japan, who had undergone a medical examination in 2002. In this examination, residents under no medication were recommended to participate. In 2002, 4789 individuals participated in the examination. Participants with serious medical conditions, who were expected to be cured soon after the examination, such as those in whom an operation was planned, might initially show high medical expenditures, which would confound the relationship between CKD and medical expenditures; however, it was difficult to detect serious medical conditions by interview at medical health checkups. Accordingly, 4086 participants, who had continuously attended the medical examination in the succeeding year (2003), were enrolled in this study. Thus, the study participants were relatively healthy, community-dwelling residents. Annual NHI claim files for over 3 years after the baseline survey within Tanba City were linked with the baseline survey data. The names and addresses of the participants were deleted from the linked data to protect their privacy. Participants with missing data $(N=7)$, and those who had a history of major CVD, such as stroke at baseline $(N=53)$, were excluded. Finally, 4026 participants (1735 men and 2291 women) were included in the analysis. The Institutional Review Board of Shiga University of Medical Science for ethical issues approved this study (No. 20-1, 2005).

\section{Baseline examination}

The baseline survey was carried out in 2003 using standardized methods in accordance with the Manual for Health Checkups under the Medical Service Law for the Aged, issued by the Japan Public Health Association in 1987. ${ }^{9}$ Serum creatinine $(\mathrm{mg}$ per $100 \mathrm{ml})$ was measured using the enzymatic method. GFR $\left(\mathrm{ml} \mathrm{min}^{-1}\right.$ per $1.73 \mathrm{~m}^{2}$ ) was calculated using the equation developed by the Japanese Society of Nephrology: $194 \times($ serum creatinine (mg per $100 \mathrm{ml}))^{-1.094} \times(\text { age }(\text { years }))^{-0.287} \times(0.739$, if female $) .{ }^{10}$ On the basis of the National Kidney Foundation (NKF) classification of CKD, ${ }^{11,12}$ the participants were classified into three groups according to their GFR: GFR $\geqslant 90,60 \leqslant$ GFR $<90$ and $30 \leqslant \mathrm{GFR}<60$. The group with GFR $\geqslant 90$ was defined as having a normal kidney function. ${ }^{11,12}$ These classifications were carried out for each calculated value of GFR.

Blood pressure was measured using an automatic sphygmomanometer after a 5-min rest. Hypertension was defined as systolic blood pressure $\geqslant 140 \mathrm{~mm} \mathrm{Hg}$ and/or diastolic blood pressure $\geqslant 90 \mathrm{~mm} \mathrm{Hg}$. Diabetes was defined as casual blood glucose $\geqslant 200 \mathrm{mg}$ per $100 \mathrm{ml}$. Hypercholesterolemia was defined as total cholesterol $\geqslant 5.69 \mathrm{mmoll}^{-1}(220 \mathrm{mg}$ per $100 \mathrm{ml})$. The participants' smoking habits were determined from interviews administered by public health nurses, and the Brinkmann index was calculated as number of cigarettes per day $\times$ years of smoking.

\section{Data analysis}

One-way analysis of variance and the $\chi^{2}$-test were used to compare risk characteristics at baseline of participants by the three GFR categories $(\mathrm{GFR} \geqslant 90 ; 60 \leqslant \mathrm{GFR}<90$ and $30 \leqslant \mathrm{GFR}<60)$. The Kruskal-Wallis test was used to compare the Brinkmann index values.

Cumulative total medical expenditures for 3 years were evaluated for each participant in each of the three GFR categories. The arithmetic mean and median of cumulative total medical expenditures were calculated for each of the three categories. The Kruskal-Wallis test was used to compare the medical expenditures among the three categories. As the distribution of medical expenditures was positively skewed, the data were logarithmically transformed to normalize the distribution; the results were then expressed as geometric means for multivariate analysis. Overall, 126 participants had cumulative total medical expenditures of 0 yen. For participants with expenditures of 0 yen, logarithmic transformations were achieved by replacing 0 yen with 1 yen. To compare cumulative total medical expenditures per person in each category, an analysis of covariance was carried out after adjusting for systolic blood pressure, plasma glucose, serum total cholesterol, body mass index (BMI) and smoking (the Brinkmann index) with Bonferroni's correction for multiple post hoc comparisons.

Furthermore, excess medical expenditures attributable to the GFR category were calculated. ${ }^{13,14}$ The excess medical expenditures were estimated as follows: $\Sigma[$ (the arithmetic mean of the cumulative total expenditures in two of the three groups, except those with GFR $\geqslant 90$, that is, (1) $60 \leqslant$ GFR $<90$ and (2) $30 \leqslant$ GFR $<60$ - the arithmetic mean of the cumulative total medical expenditures in the GFR $\geqslant 90$ group) $\times$ (the numbers of individuals in two of the three groups, except those with GFR $\geqslant 90)$ ]. The proportion of excess cumulative medical expenditures to the entire cumulative total medical expenditures of the population was also examined.

The statistical package, SPSS 15.0J (SPSS, Tokyo, Japan), for Windows was used to carry out these analyses. All $P$-values were two-tailed, and the significance level was established at $P<0.05$.

\section{RESULTS}

The mean age of the study population was 63.1 years (males, 63.1 years; females, 63.1 years), and the mean GFR value of all participants was 73.8 (males, 73.9; females, 73.7) $\mathrm{ml} \mathrm{min}^{-1}$ per $1.73 \mathrm{~m}^{2}$.

Table 1 summarizes the baseline risk characteristics of the participants classified into three groups on the basis of GFR according to the definition of CKD; $17.7 \%$ of participants had CKD with GFR $<60$ at baseline. The mean values of age, serum total cholesterol and BMI for both sexes were higher in participants with decreased GFR. Systolic blood pressure and the prevalence of hypertension were higher in male participants with $\mathrm{CKD}$ than in participants without $\mathrm{CKD}$, whereas the Brinkmann index in male participants and the casual plasma glucose in female participants were lower in participants with decreased GFR.

Table 2 shows the cumulative total medical expenditures per person (Japanese yen) grouped by sex and GFR. The median of the medical expenditures showed significant differences among the three categories. The geometric means of the medical expenditures after adjusting for several confounding factors also showed significant differences among the three categories. Bonferroni's correction for multiple post hoc comparisons showed a significant difference between the adjusted geometric mean of the participants with $G F R \geqslant 90$ and that of the participants with $60 \leqslant$ GFR $<90$ and those with $30 \leqslant$ GFR $<60$.

The calculated excess cumulative total medical expenditures attributable to the $60 \leqslant \mathrm{GFR}<90$ group and to the $30 \leqslant \mathrm{GFR}<60$ group were 303947460 yen and 171774756 yen, respectively. Figure 1 shows the excess cumulative total medical expenditure related to CKD for each group as a proportion of the cumulative total medical expenditures of the entire population. The proportion of the excess cumulative total medical expenditures related to CKD for the participants with $60 \leqslant \mathrm{GFR}<90(n=2670)$ was $11.5 \%$, and that for the participants with $30 \leqslant \mathrm{GFR}<60(n=711)$ was $6.5 \%$.

As the estimation of GFR tends to be underestimated among those with GFR $>60$, we divided the source population into two groups $(G F R \geqslant 60$ and $G F R<60)$. The arithmetic mean was 209238 yen in GFR $\geqslant 60$ and 259208 yen in GFR $<60$. The adjusted geometric mean was 69703 yen in GFR $\geqslant 60$ and 112308 yen in GFR $<60$. The proportion of excess medical expenditure was $4.0 \%$ in GFR $<60$.

\section{DISCUSSION}

In this study, there was a negative correlation between GFR and the arithmetic and geometric means of personal medical expenditures. However, the excess total medical expenditures might be higher among the participants with $60 \leqslant \mathrm{GFR}<90$ than among those with 
Table 1 Baseline risk characteristics of 4026 participants by sex and kidney function in 2003 in Tanba City, Japan

\begin{tabular}{|c|c|c|c|c|}
\hline & \multicolumn{3}{|c|}{ GFR $\left(\mathrm{m} \mathrm{min}^{-1}\right.$ per $\left.1.73 \mathrm{~m}^{2}\right)$} & \multirow[b]{2}{*}{ P-value } \\
\hline & $G F R \geqslant 90$ & $60 \leqslant G F R<90$ & $30 \leqslant G F R<60(C K D)$ & \\
\hline No. of participants & 207 & 1198 & 330 & \\
\hline Age (years) & $58.0 \pm 10.2$ & $63.1 \pm 8.5$ & $66.7 \pm 5.7$ & $<0.001$ \\
\hline GFR $\left(\mathrm{ml} \mathrm{min}{ }^{-1}\right.$ per $\left.1.73 \mathrm{~m}^{2}\right)$ & $101.2 \pm 9.2$ & $74.6 \pm 8.0$ & $54.0 \pm 6.0$ & $<0.001$ \\
\hline Serum total cholesterol (mg per $100 \mathrm{ml}$ ) & $199 \pm 37$ & $205 \pm 33$ & $206 \pm 32$ & $<0.05$ \\
\hline Plasma glucose (mg per $100 \mathrm{ml}$ ) & $105 \pm 35$ & $101 \pm 23$ & $101 \pm 31$ & 0.13 \\
\hline Body mass index $\left(\mathrm{kg} \mathrm{m}^{-2}\right)$ & $22.7 \pm 3.0$ & $23.2 \pm 3.0$ & $23.8 \pm 2.8$ & $<0.001$ \\
\hline Brinkmann indexa & 477 & 444 & 300 & $<0.001$ \\
\hline Hypertension (\%) & 39.6 & 46.2 & 51.2 & $<0.05$ \\
\hline Diabetes mellitus (\%) & 2.4 & 0.9 & 2.1 & 0.08 \\
\hline Age (years) & $61.1 \pm 7.8$ & $63.3 \pm 7.8$ & $64.8 \pm 6.3$ & $<0.001$ \\
\hline GFR $\left(\mathrm{ml} \mathrm{min}-1\right.$ per $\left.1.73 \mathrm{~m}^{2}\right)$ & $98.0 \pm 11.3$ & $72.2 \pm 7.2$ & $51.8 \pm 5.6$ & $<0.001$ \\
\hline Serum creatinine (mg per $100 \mathrm{ml}$ ) & $0.48 \pm 0.04$ & $0.63 \pm 0.06$ & $0.86 \pm 0.10$ & $<0.001$ \\
\hline Systolic blood pressure (mm Hg) & $133 \pm 19$ & $134 \pm 19$ & $134 \pm 19$ & 0.56 \\
\hline Serum total cholesterol (mg per $100 \mathrm{ml})$ & $216 \pm 35$ & $222 \pm 33$ & $225 \pm 34$ & $<0.001$ \\
\hline Plasma glucose (mg per $100 \mathrm{ml}$ ) & $100 \pm 20$ & $96 \pm 16$ & $93 \pm 19$ & $<0.001$ \\
\hline Body mass index $\left(\mathrm{kg} \mathrm{m}^{-2}\right)$ & $22.5 \pm 3.0$ & $22.8 \pm 3.1$ & $23.2 \pm 3.2$ & $<0.01$ \\
\hline Brinkmann index & 3.0 & 7.4 & 5.9 & 0.22 \\
\hline Hypertension (\%) & 41.6 & 40.5 & 39.6 & 0.85 \\
\hline Diabetes mellitus (\%) & 0.7 & 0.1 & 0.3 & 0.09 \\
\hline Hypercholesterolemia (\%) & 24.0 & 27.9 & 30.7 & 0.14 \\
\hline
\end{tabular}

Abbreviation: GFR, glomerular filtration rate.

Values are mean \pm s.d. or the $\%$ of participants in that category. One-way analysis of variance for continuous variables, $\chi^{2}$-test for categorical variables.

akruskal-Wallis test.

$30 \leqslant \mathrm{GFR}<60$, because the number of participants with $60 \leqslant \mathrm{GFR}$ $<90$ was much higher than that of participants with $30 \leqslant \mathrm{GFR}<60$. Accordingly, the prevention of mild CKD is very important from the viewpoint of national medical expenditures.

In this study, the equation developed by the Japanese Society of Nephrology for GFR estimation ${ }^{10}$ was used, and the definition of CKD from The Kidney Disease Outcome Quality Initiative (K/DOQI) practice guideline that was published in 2002 by the National Kidney Foundation $(\mathrm{NKF})^{11,12}$ was adopted. According to earlier community-based population studies in Japan, ${ }^{4,5,15}$ which used the equation developed at the Cleveland Clinic laboratory for the MDRD (Modification of Diet in Renal Disease) study for GFR estimation, ${ }^{16,17}$ the prevalence of $\mathrm{CKD}$ was $\sim 10 \%$ or less. In this study, the prevalence of CKD was $17.7 \%$. This difference might be explained by the equation or by the high mean age of the participants in this study. Zhang et al. ${ }^{18}$ reported that the median prevalence of $\mathrm{CKD}$ was $7.2 \%$ in persons aged 30 years or older, and the prevalence of CKD varied from 23.4 to $35.8 \%$ in persons aged 64 years or older. Considering the mean age of our participants (63.1 years), our result was essentially consistent with the result of Zhang's study. Accordingly, the present result may be representative of medical expenditure data among participants for health checkups in Japanese local cities, where the mean age of the residents is relatively high.

There was an inverse correlation between GFR and the arithmetic mean of the total medical expenditures. Furthermore, after adjusting for several confounding factors, such as systolic blood pressure and plasma glucose, the geometric means of the medical expenditures also showed an inverse correlation with GFR category. According to earlier studies, CKD is associated with cardiovascular mortality and morbidity. ${ }^{3-5}$ The etiology of the increased risk of CVD in CKD patients is still unknown, but it may be in part because of shared CVD risk factors, including hypertension, diabetes, obesity, lipid abnormalities and smoking. ${ }^{19-23}$ Acute CVD related to CKD, such as stroke and myocardial infarction, may increase medical expenditures because of hospitalization and intensive care. Accordingly, an individual with CKD faces high future medical expenditures. Furthermore, although the residents taking no medication were recommended to participate in the baseline survey, no information about the details of medication after the baseline survey was available. Some participants with decreased GFR might have had treatment for CVD risk factors, such as hypertension and diabetes. The treatment of CVD risk factors may be another reason for increased medical expenditures among individuals with CKD.

Nevertheless, from the perspective of the entire population, the participants with $60 \leqslant \mathrm{GFR}<90$ have a large medical economic effect, because the number of participants with $60 \leqslant \mathrm{GFR}<90$ was very large. Early screening of mild kidney dysfunction by serum creatinine measurement and early intervention to stop progression are important. Moreover, we would expect an $18 \%$ reduction in total population medical expenditures if each individual were to maintain a normal GFR by controlling CKD. 
Table 2 Cumulative total medical expenditures per person grouped by sex and GFR, after 3 years of follow-up in Tanba City, Japan

\begin{tabular}{|c|c|c|c|c|}
\hline \multirow[b]{2}{*}{ GFR category } & \multirow[b]{2}{*}{$\begin{array}{c}\text { No. of } \\
\text { participants }\end{array}$} & \multicolumn{3}{|c|}{$\begin{array}{c}\text { Cumulative total medical expenditures } \\
\text { per person (Japanese yen) }\end{array}$} \\
\hline & & $\begin{array}{c}\text { Arithmetic } \\
\text { mean }\end{array}$ & Median & $\begin{array}{c}\text { Adjusted } \\
\text { geometric mea }\end{array}$ \\
\hline \multicolumn{5}{|l|}{ Male and female } \\
\hline GFR $\geqslant 90$ & 645 & 536027 & 308570 & 167879 \\
\hline $60 \leqslant$ GFR $<90$ & 2670 & 649865 & 403850 & $210660 *$ \\
\hline \multirow[t]{2}{*}{$30 \leqslant$ GFR $<60$} & 711 & 777623 & 511050 & $330050 *$ \\
\hline & & & $P<0.001^{a}$ & $P<0.001^{b}$ \\
\hline \multicolumn{5}{|l|}{ Male } \\
\hline GFR $\geqslant 90$ & 207 & 457775 & 229700 & 132720 \\
\hline $60 \leqslant$ GFR $<90$ & 1198 & 648106 & 351665 & 157157 \\
\hline \multirow[t]{2}{*}{$30 \leqslant$ GFR $<60$} & 330 & 813277 & 552025 & $319017^{*}$ \\
\hline & & & $P<0.001^{a}$ & $P<0.001^{b}$ \\
\hline \multicolumn{5}{|l|}{ Female } \\
\hline $\mathrm{GFR} \geqslant 90$ & 438 & 573010 & 362010 & 190118 \\
\hline $60 \leqslant$ GFR $<90$ & 1472 & 651296 & 439510 & $265375^{*}$ \\
\hline \multirow[t]{2}{*}{$30 \leqslant$ GFR $<60$} & 381 & 746741 & 475330 & $343898^{*}$ \\
\hline & & & $P<0.001^{a}$ & $P<0.001^{b}$ \\
\hline
\end{tabular}

Abbreviation: GFR, glomerular filtration rate.

*Bonferroni correction for multiple post hoc comparisons. Significance, between GFR $\geqslant 90$ and other categories, $P<0.05$.

aKruskal-Wallis test.

bMultivariate analysis of covariance adjusted for systolic blood pressure $(\mathrm{mm} \mathrm{Hg})$, plasma glucose $(\mathrm{mg}$ per $100 \mathrm{ml}$ ), serum total cholesterol ( $\mathrm{mg}$ per $100 \mathrm{ml}$ ), body mass index and smoking habit (Brinkmann index).

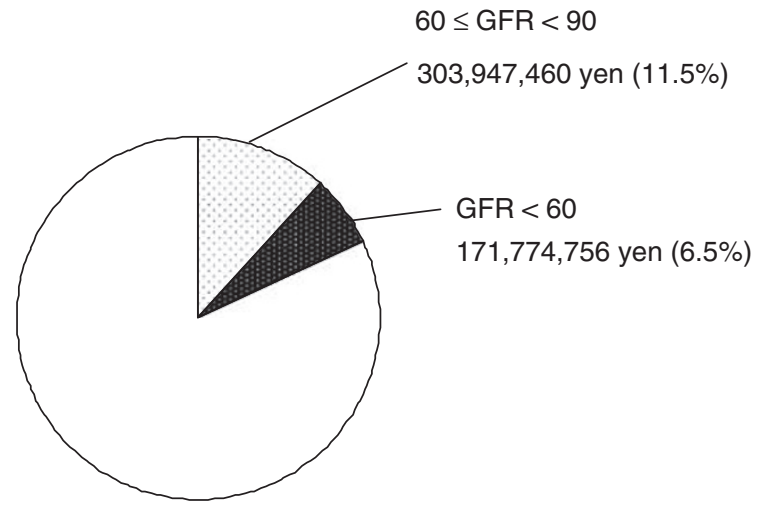

Figure 1 Proportion (\%) of excess medical expenditures related to chronic kidney disease (CKD) in the whole population after a 3-year follow-up in Tanba City, Japan. White area represents predicted medical expenditures if all participants were of glomerular filtration rate (GFR) $\geqslant 90 \mathrm{ml} \mathrm{min}^{-1}$ per $1.73 \mathrm{~m}^{2}$.

The interplay between CKD and CVD risk factors leads to enhanced cardiovascular risk. ${ }^{24-26}$ Accordingly, the prevention of hypertension and diabetes mellitus by lifestyle modification, such as reducing dietary salt intake, decreasing body weight, increasing physical activity and reducing alcohol intake, ${ }^{27-31}$ is very important for preventing CKD. Furthermore, angiotensin-converting enzyme inhibitors or angiotensin II type I blockers, which lower intra-glomerular pressure, protect against renal injury ${ }^{32}$ and lower the risk of CVD mortality in individuals with hypertension or diabetes mellitus. ${ }^{33,34}$
In this study, only the residents with no medication were invited to participate. However, practically, CKD is often accompanied by diseases, such as hypertension, diabetes and CVDs, which were not taken into consideration in this study. Therefore, the medical expenditure examined in this study reflects only a certain part of the whole expenditure for CKD.

This study has several limitations. First, the medical expenditures of persons who died or moved during the follow-up period could not be determined. As earlier studies showed that CKD is a risk factor for CVD or all-cause mortality, ${ }^{35-37}$ the effect of CKD on medical expenditures in this study was underestimated. In addition, the tendency of the relationship between kidney function and medical expenditures was the same in the result of this study when we analyzed the medical expenditures by each year of follow-up. Second, none of the participants had severely decreased kidney function $(\mathrm{GFR}<30)$, because such individuals did not participate in the medical examination. Therefore, the relationship between CKD and medical expenditures was also underestimated. Third, the details of the participants' medication status were not available in this study. However, participants taking no medications were invited to participate in the baseline survey. Fourth, the estimation of GFR may be underestimated among the participants with GFR $>60 .{ }^{10}$ The development of the new equation might be needed to estimate the accurate GFR of the individuals with GFR $>60$. Finally, the details of the names of diseases causing increased medical expenditures were unknown.

In conclusion, $\mathrm{CKD}$ may be an important predictor for excess medical expenditures for individuals and for the population as a whole. To maintain kidney function and contain medical expenditures, appropriate strategies, such as regular serum creatinine screening, are needed to identify CKD and intervene in high-risk individuals with CKD.

\section{ACKNOWLEDGEMENTS}

This research was supported by a Grant-in-Aid from the Ministry of Health, Labor, and Welfare, Health and Labor Sciences Research Grants, Japan (Research on Health Services: H17-Kenkou-007, Comprehensive Research on Cardiovascular and Life-Related Diseases: H18-Junkankitou[Seishuu]-Ippan012, Comprehensive Research on Cardiovascular and Life-Style Related Diseases: H19-Junkankitou[Seishuu]-Ippan-012, and Comprehensive Research on Cardiovascular and Life-Style Related Diseases: H20-Junkankitou [Seishuu]-Ippan-013).

1 Iseki K. Chronic kidney disease in Japan. Int Med 2008; 47: 681-689.

2 Thorp ML, Eastman L. Potential application of the National Kidney Foundation's chronic kidney disease guidelines in a managed care setting. Am J Manag Care 2004; 10: 417-422.

3 Culleton BF, Larson MG, Wilson PWF, Evans JC, Parfrey PS, Levy D. Cardiovascular disease and mortality in a community-based cohort with mild renal insufficiency. Kidney Int 1999; 56: 2214-2219.

4 Ninomiya T, Kiyohara Y, Kubo M, Tanizaki Y, Doi Y, Okubo K, Wakugawa Y, Hata J, Oishi Y, Shikata K, Yonemoto K, Hirakata H, lida M. Chronic kidney disease and cardiovascular disease in a general Japanese population: The Hisayama Study. Kidney Int 2005; 68: 228-236.

5 Irie $\mathrm{F}$, Iso $\mathrm{H}$, Sairenchi T, Fukasawa N, Yamagishi K, Ikehara S, Kanashiki M, Saito $\mathrm{Y}$, Ota $\mathrm{H}$, Nose $\mathrm{T}$. The relationship of proteinuria, serum creatinine, glomerular filtration rate with cardiovascular disease mortality in Japanese general population. Kidney Int 2006; 69: 1264-1271.

6 Health and Welfare Statistics Association. 2004 Kokumin Eisei no Doko (Trend for National Health and Hygiene, Japan). Health and Welfare Statistics Association: Tokyo, 2004 (in Japanese).

7 Health and Welfare Statistics Association. 2004 Hoken to Nenkin no Doko (Trend for Insurance and Pension, Japan). Health and Welfare Statistics Association: Tokyo, 2004 (in Japanese).

8 Health and Welfare Statistics Association. 2007 Kokumin Eisei No Doko (Trend for National Health and Hygiene, Japan). Health and Welfare Statistics Association: Tokyo, 2007 (in Japanese). 
9 The Ministry of Health and Welfare. Manual for Health Check-ups Under Medical Service Law for the Aged. Japan Public Health Association: Tokyo, 1987 (in Japanese). 10 http://www.jsn.or.jp/jsn_new/index.html (Accessed on 28 August 2008).

11 National Kidney Foundation. K/DOQI clinical practice guidelines for chronic kidney disease: evaluation, classification, and stratification. Am J Kidney Dis 2002; 39 (Suppl 1): S1-S266.

12 Levey AS, Coresh J, Balk E, Kausz AT, Levin A, Steffes MW, Hogg RJ, Perrone RD, Lau $J$, Eknoyan G. National Kidney Foundation practice guidelines for chronic kidney disease: evaluation, classification, and stratification. Ann Intern Med 2003; 139: 137-147.

13 Nakamura K, Okamura T, Kanda H, Hayakawa T, Kadowaki T, Okayama A, Ueshima H, for the Health Promotion Research Committee of the Shiga National Health Insurance Organizations. Impact of hypertension on medical economics: a 10-year follow-up study of National Health Insurance in Shiga, Japan. Hypertens Res 2005; 28 : 859-864.

14 Okamura T, Nakamura K, Kanda H, Hayakawa T, Hozawa A, Murakami Y, Kadowaki T, Kita Y, Okayama A, Ueshima H, Health Promotion Research Committee, Shiga National Health Insurance Organizations. Effect of combined cardiovascular risk factors on individual and population medical expenditures: a 10-year cohort study of national health insurance in a Japanese population. Circ J 2007; 71: 807-813.

15 Nakamura K, Okamura T, Hayakawa T, Kadowaki T, Kita Y, Ohnishi H, Saitoh S, Sakata K, Okayama A, Ueshima H, for the NIPPON DATA90 Research Group. Chronic kidney disease is a risk factor for cardiovascular death in a community-based population in Japan -NIPPON DATA90-. Circ J 2006; 70: 954-959.

16 Levey AS, Bosch JP, Lewis JB, Greene T, Rogers N, Roth D, for the Modification of Diet in Renal Disease Study Group. A more accurate method to estimate glomerular filtration rate from serum creatinine. Ann Intern Med 1999; 130: 461-469.

17 Levey AS, Greene T, Kusek JW, Beck GJ, Group MS. A simplified equation to predict glomerular filtration rate from serum creatinine (abstract). J Am Soc Nephrol 2000; 11: A0828.

18 Zhang QL, Rothenbacher D. Prevalence of chronic kidney disease in population-based studies: Systematic review. BMC Public Health 2008; 8: 117.

19 Bleyer AJ, Shamanski LR, Burke GL, Hansen KJ, Appel RG. Tobacco, hypertension, and vascular disease: risk factors for renal function decline in an older population. Kidney Int 2000; 57: 2072-2079.

20 Fox CS, Larson MG, Leip EP, Culleton B, Wilson PW, Levy D. Predictors of new-onset kidney disease in a community-based population. JAMA 2004; 291: 844-850.

21 Manttari M, Tiula E, Alikoski T, Manninen V. Effects of hypertension and dyslipidemia on the decline in renal function. Hypertension 1995; 26: 670-675.

22 Mutner P, Coresh J, Smith JC, Eckfeldt J, Klag MJ. Plasma lipids and risk of developing renal dysfunction: the atherosclerosis risk in communities study. Kidney Int 2000; 58: 293-301.

23 Tozawa M, Iseki K, Iseki C, Oshiro S, Ikemiya Y, Takishita S. Influence of smoking and obesity on the development of proteinuria. Kidney Int 2002; 62: 956-962.
24 Parikh NI, Hwang SJ, Larson MG, Meigs JB, Levy D, Fox CS. Cardiovascular disease risk factors in chronic kidney disease. Overall burden and rates of treatment and control. Arch Intern Med 2006; 166: 1884-1981.

25 Weiner DE. Causes and consequences of chronic kidney disease: implications for managed health care. J Manag Care Pharm 2007; 13 (suppl): S1-S9.

26 Keane WF. Metabolic pathogenesis of cardiorenal disease. Am J Kidney Dis 2001; 38 : 1372-1375.

27 Cappuccio FP, Markandu ND, Carney C, Sagnella GA, MacGregor GA. Double-blind randomized trial of modest salt restriction in older people. Lancet 1997; 350: $850-854$.

28 Jones DW. Body weight and blood pressure. Effects of weight reduction on hypertension. Am J Hypertens 1996; 9: 50S-54S.

29 Ueshima H, Mikawa K, Baba S, Sasaki S, Ozawa H, Tsushima M, Kawaguchi A, Omae T, Katayama Y, Kayamori Y. Effect of reduced alcohol consumption on blood pressure in untreated hypertensive men. Hypertension 1993; 21: 248-252.

30 Okada T, Hayashi T, Tsumura K, Suematsu C, Endo G, Fujii S. Leisure-time physical activity at weekends and the risk of Type 2 diabetes mellitus in Japanese men: the Osaka Health Survey. Diabet Med 2000; 17: 53-58.

31 Fujimoto WY, Jablonski KA, Bray GA, Kriska A, Barrett-Connor E, Haffner S, Hanson R, O Hill J, Hubbard V, Stamm E, Pi-Sunyer FX, for the Diabetes Prevention Program Research Group. Body size and shape changes and the risk of diabetes in the diabetes prevention program. Diabetes 2007; 56: 1680-1685.

32 Karalliedde J, Viberti G. Evidence for renoprotection by blockade of the reninangiotensin aldosterone system in hypertension and diabetes. I Hum Hypertens 2006; 20: 239-253.

33 Collins R, Peto R, MacMahon S, Hebert P, Fiebach NH, Eberlein KA, Godwin J, Qizilbash N, Taylor JO, Hennekens CH. Blood pressure, stroke, and coronary heart disease. Part 2, short-term reductions in blood pressure: overview of randomized drug trials in their epidemiological context. Lancet 1990; 335: 827-838.

34 Stratton IM, Adler AI, Neil HAW, Matthews DR, Manley SE, Cull CA, Hadden D, Turner RC, Holman RR. Association of glycemia with macrovascular and microvascular complications of type 2 diabetes (UKPDS 35): prospective observational study. BMJ 2000; 321: 405-412.

35 Manjunath G, Tighiouart H, Ibraham H, MacLeod B, Salem DN, Griffith JL, Coresh J, Levey AS, Sarnak MJ. Level of kidney function as a risk factor for atherosclerotic cardiovascular outcomes in the community. J Am Coll Cardiol 2003; 41: 47-55.

36 Go AS, Chertow GM, Fan D, McCulloch CE, Hsu C. Chronic kidney disease and the risks of death, cardiovascular events, and hospitalization. N Eng J Med 2004; 351: 1296-1305.

37 Weiner DE, Tighiouart H, Amin MG, Stark PC, Macleod B, Griffith JL, Salem DN, Levey AS, Sarnak MJ. Chronic kidney disease as a risk factor for cardiovascular disease and all-cause mortality: a pooled analysis of community-based studies. J Am Soc Nephrol 2004; 15: 1307-1315. 